\title{
Strategies to Minimize Various Stress-Related Freeze-Thaw Damages During Conventional Cryopreservation of Mammalian Spermatozoa
}

\author{
Abhishek Kumar, J.K. Prasad, N. Srivastava, and S.K. Ghosh
}

The aim of the article is to report a review on different sperm cryopreservation techniques, various stress-related freeze-thaw damages altering sperm structure and function during conventional cryopreservation, and strategies to minimize these stresses. Sperm cryopreservation has allowed indefinite storage and successful transportation of valuable germplasm from proven sites at distant locations, for genetic upgradation through implementation of reproductive techniques, such as artificial insemination. Different techniques for sperm cryopreservation have been proposed such as conventional freezing techniques, directional freezing, and sperm vitrification. Drawbacks related to conventional freezing methods, such as heterogeneous ice nucleation and repeated freeze-thaw cycles at the ice front that disrupts and kill sperm cells, led to the emergence of the directional freezing technique. Sperm vitrification is advantageous as there is no ice crystal-induced physical damages to sperm. However, sperm vitrification has less applicability as encouraging results are only reported in human, dog, and cat. In spite of several drawbacks, conventional freezing techniques are still most widely used for sperm cryopreservation. Spermatozoa experience stresses in the form of cold shock, osmotic stress, and mainly oxidative stress during conventional cryopreservation ultimately reduces the sperm viability and fertility. Several attempts have been made in the past to minimize all these stresses individually or in combination. Membrane fluidity was increased to prevent the cold shock and cryocapacitation-like changes by the addition of cholesterol to the membrane. Antifreeze proteins were added in semen extender to minimize freeze-thaw damages due to heterogeneous ice nucleation and ice recrystallization. Oxidative stress was reduced either by neutralizing reactive oxygen species (ROS) through enzymatic, nonenzymatic, plant-based antioxidants or reductants; or by minimizing the level of sources like the semen radiation exposure, leucocytes, and dead and defective spermatozoa, which lead to ROS production during the semen cryopreservation process. A novel approach of minimizing oxidative stress was to reduce the oxygen tension in sperm microenvironment that is, extender by partial deoxygenation process, as a number of literatures pointed out direct link of $\mathrm{O}_{2}$ with ROS production. When compared with other strategies, partial deoxygenation of semen extender with $\mathrm{N}_{2}$ gassing is found as a cost-effective, comparatively easy and a potential approach to large-scale frozen semen production.

Keywords: sperm cryopreservation, conventional freezing, directional freezing, sperm vitrification, cold shock, osmotic stress, oxidative stress

\section{Introduction}

$\mathrm{S}$ PERM CRYOPRESERVATION HAS made possible the successful implementation of reproductive techniques such as artificial insemination (AI) and in vitro fertilization (IVF) worldwide. ${ }^{1}$ AI with frozen semen became essential in breeding and selection criteria for enhancing the production potential of domestic animal species. Conventional freezing techniques are most widely used for sperm cryopreservation in spite of advances in the form of directional freezing technique and sperm vitrification. Freezing during cryopreservation is mainly done to halt the metabolic processes of the spermatozoa, allowing indefinite storage for future use or for transportation to distant locations. ${ }^{2}$ On the other hand, the cryopreservation process is detrimental to sperm viability and fertility. ${ }^{3}$ Dramatic changes in temperature, osmotic or toxic stresses due to cryoprotectants and mainly the effects of reactive oxygen species (ROS) due to 
oxidative stress, result in semen cryopreservation leading to structural and functional damages to sperm. The present review deals with different techniques of sperm cryopreservation and describes in detail various stress-related freeze-thaw damages during conventional cryopreservation, with possible strategies to minimize these stresses. It mainly covers domestic species while other species like human and wildlife species are also mentioned wherever required, considering the diversity of the topic.

\section{Sperm Cryopreservation Techniques}

\section{Conventional freezing technique}

Freezing methods for sperm cryopreservation can be broadly characterized into three basic modes of freezing that is, Equiaxed freezing, directional freezing, and vitrification. Equiaxed (star-shaped ice crystals) freezing, is also known as programmable or nonprogrammable conventional freezing, of which most widely used is the manual freezing technique. ${ }^{4}$ In this technique, 0.25 - or 0.5 -mL plastic straws filled with extended semen are placed in contact with liquid nitrogen $\left(\mathrm{LN}_{2}\right)$ vapor at $4-5 \mathrm{~cm}$ height above $\mathrm{LN}_{2}$ for a time not greater than 15 minutes (where 10 minutes is recommended), before being plunged into the $\mathrm{LN}_{2}$ for storage. The freezing rate is $\sim 60^{\circ} \mathrm{C} / \mathrm{min}^{5}$ In programmable freezing, different freezing/cooling rates for varied temperature ranges are programmed in a biofreezer for freezing the straws before plunging in $\mathrm{LN}_{2}$. It is species specific and varies from species to species depending on sperm quality or cryosurvivability after the freeze-thaw process. ${ }^{5}$

To minimize cryoinjury, the cooling rate should be optimum and it should neither be high (physical damage due to intracellular ice crystallizations), nor be low (osmotic damage/architectural loss due to excessive cellular dehydration in response to extracellular ice crystallizations, "Solution effect"). The same principle is applicable for the thawing rate as low thawing rates over the critical temperature range $\left(-60^{\circ} \mathrm{C}\right.$ to $\left.-15^{\circ} \mathrm{C}\right)$ cause physical damage to sperm $^{6}$ due to ice recrystallization (smaller ice crystals agglomerate to form deformed or bigger ice crystals), and the high thawing rate causes osmotic damage to sperm as cryoprotectants are unable to leave the cell fast enough, resulting in osmotic entry of extracellular water inside the cell, cell swelling, and finally cell death. ${ }^{7}$ Generally, thawing is done at $37^{\circ} \mathrm{C}$ for 30 seconds (ranging $45-60$ seconds). Improper thawing procedures such as rolling of straws between hands and placing under the armpit or in pockets are often seen at the field level, which leads to sperm damage and deterioration of post-thaw semen quality. Therefore, frozen semen needs to be thawed well before insemination and needs to be inseminated as soon as it is thawed. Once straws are taken out of the container, they should not be put back into a $\mathrm{LN}_{2}$ container again. However, the overall success of sperm cryopreservation also depends on factors such as the type of freezing media and cryoprotectants, lecithin or protein source (egg yolk, soya milk, or lowdensity lipoproteins), and mechanical stresses involved in the processing of semen, like pipetting, dilution, mixing, packaging, storage, and transfer.

Drawbacks related to conventional freezing methods are (1) Heterogeneous ice nucleation or uncontrolled ice crystal growth in terms of both velocity and morphology that dis- rupts and kills sperm cells, (2) Inefficient latent heat dissipation that is, repeated freeze-thaw cycles at the ice front causing mechanical damage to cells. These drawbacks led to the emergence of a new cryopreservation technique that is, directional freezing technique.

\section{Directional freezing technique}

The alternative technique for sperm cryopreservation is the directional freezing technique. In this technique, a multithermal gradient device is used. ${ }^{8}$ After dilution with freezing extender, semen is cooled to $4-5^{\circ} \mathrm{C}$ at $\approx 0.3^{\circ} \mathrm{C} / \mathrm{min}$ and packaged in prechilled hollow tubes $(5,8$, or $12 \mathrm{~mL})$. Tubes are advanced through a linear temperature gradient, from $5^{\circ} \mathrm{C}$ (warm block) to $-50^{\circ} \mathrm{C}$ (cold block) at a constant velocity that is, $1 \mathrm{~mm} / \mathrm{sec}(1.0-1.5 \mathrm{~mm} / \mathrm{s})$. Thereafter, seeding is done for $\sim 60$ seconds and through a cold block at its other end, tubes are moved to a collection chamber $\left(-100^{\circ} \mathrm{C}\right)$. Then, these tubes are collected and transferred into $\mathrm{LN}_{2}$ for storage. For evaluation, tubes are first air thawed at ambient temperature for 90 seconds and then placed into a specialized hollow tube thawing unit (Interface Multigrad Technology, Israel) inside a water bath at $37^{\circ} \mathrm{C}$ for 60 seconds. Saragusty et al. ${ }^{9}$ proposed that when freezing a large volume of semen by the directional freezing technique, a controlled ice nucleation (CIN) or seeding stage is not required. Later, double freezing technique was introduced to make use of semen of valuable sire, frozen, and stored by directional freezing technique for AI at distant locations. ${ }^{10}$

Continuous seeding, CIN, homogeneous cooling, efficient latent heat dissipation, and higher storage economy make this technique advantageous and superior than the conventional freezing methods. ${ }^{11}$ It allows freezing of large volumes of semen in reusable tubes, reduces mechanical damage to sperm, resulting in a high survival rate after the freeze-thaw process. ${ }^{11,12}$ Directional freezing for sperm cryopreservation has been reported in a wide range of domestic and wildlife species ${ }^{13-17}$ and also found to be superior to conventional freezing in straws.

\section{Sperm vitrification}

Vitrification is a process of transforming a solution containing high concentration of cryoprotectant in a glass-like (Latin "Vitreum") state without ice crystal formation through an ultrarapid cooling process. ${ }^{18}$ Three important factors, which affect the probability of success of vitrification, are cooling rate, viscosity, and volume. High cooling rate, high viscosity, and low volume that is, in cryo-loops $(1 \mu \mathrm{L})$, droplets $(30 \mu \mathrm{L})$, and open pulled straw $(5 \mu \mathrm{L})$ increases the probability of a successful outcome. ${ }^{12}$

It is a rapidly emerging technique for cryopreservation and advantageous compared with conventional cryopreservation in many aspects. It involves short equilibration times, fast cooling rates, no expensive equipment such as a programmed biofreezer, and there is no physical damage to the cells due to ice crystals. It is relatively cheaper, much faster, and simpler in application than conventional freezing methods.

Vitrification of frog spermatozoa was first reported early in 1938 by Basile J. Luyet and Eugene L. Hodapp. In spite of this, this technique had only been investigated and 
successfully applied to oocytes and embryos of different mammalian species. ${ }^{19-22}$ It was due to lethal osmotic effects of a high percentage of permeable cryoprotectants (30-50\%) used in vitrification media on spermatozoa, which had limited its successful application. However, Isachenko et $\mathrm{al}^{23}$ demonstrated that vitrification of spermatozoa without permeable cryoprotectants was possible and it resulted in a higher motility after thawing as compared with conventional freezing with cryoprotectants. Conventional freezing of human spermatozoa in $0.25 \mathrm{~mL}$ insemination straws with permeable cryoprotectant was compared with aseptic cryoprotectant-free vitrification method (vitrification media: human tubal fluid supplemented with $1 \%$ human serum albumin and $0.25 \mathrm{M}$ sucrose). For vitrification, a $0.25 \mathrm{~mL}$ insemination straw was filled with $100 \mu \mathrm{L}$ of the sperm suspension, placed in a $0.5 \mathrm{~mL}$ insemination straw, which was hermetically closed at both ends and directly plunged into $\mathrm{LN}_{2}$. For semen evaluation, thawing was done by immersing the straw into a water bath at $42^{\circ} \mathrm{C}$ for 20 seconds. Both cryopreservation techniques demonstrated similar results. ${ }^{24}$

Vitrification of human spermatozoa has been extensively studied and modified for over a decade ${ }^{25-27}$ because human spermatozoa are the smallest and shows maximum cryostability as compared with spermatozoa of animals. Spermatozoa of human $>$ stallion $>\operatorname{dog}>$ cat $>$ rabbit $>$ ram $>$ bull $>$ boar have cryostability in decreasing order, and sperm of bull and boar have the lowest stability to cold shock due to their big blade-shaped flat head, therefore, less likely to sustain a vitrification process. In general, there is negative correlation between the sperm head size and vitrification success. ${ }^{28}$ Sperm vitrification has also been reported in $\operatorname{dog},{ }^{29}$ cat, ${ }^{30}$ and ram ${ }^{31,32}$ with variable results.

In spite of several advantages of the directional freezing technique and sperm vitrification, conventional cryopreservation is the most commonly used worldwide technique for freezing of domestic animal sperm cells. Therefore, this review will now focus on various stress-related freeze-thaw damage that result in altering sperm structure and function during conventional cryopreservation, and strategies to minimize these stresses are discussed in the following section.

\section{Temperature stress (cold shock)}

Temperature stress or cold shock is related to phase change in lipids and the altered functional state of membranes $^{33,34}$ as freeze fracture studies of membranes before, during, and after cooling clearly showed the phase separation events. ${ }^{35,36}$ One way to prevent membrane damage due to phase change from fluid to the gel state was to increase the membrane fluidity at low temperatures by adding cholesterol to the membrane. Different concentrations of cholesterol-loaded-cyclodextrins (CLC) have been used in cattle, ${ }^{37}$ buffalo bulls, ${ }^{38}$ rams, ${ }^{39}$ stallions, ${ }^{40}$ and boars ${ }^{41}$ to minimize cryocapacitation-like changes and to improve cryosurvivability of spermatozoa in this regard.

\section{Osmotic stress}

Addition of cryoprotectants leads to osmotic or toxic stress, which depends upon the relative permeability of that particular cryoprotectant. ${ }^{42}$ When a solution is cooled below the freezing point, ice crystals are nucleated and pure water crystallizes out as ice. The solutes are dissolved in the remaining liquid water fraction and the osmotic strength of the solution rises, causing a solution effect. These stresses are due to osmotic pressure change in the unfrozen fractions as a result of ice crystal formation. ${ }^{43}$ One way to reduce freezethaw damages or stresses, due to heterogeneous ice nucleation and ice recrystallization, was addition of antifreeze proteins (AFPs) in semen extender to modify or inhibit ice crystal formation. These AFPs are produced by polar fish, some species of insects like beetle (Dendroides canadensis) and winter/cold-acclimated plants like winter rye (Secale cereale), carrot (Daucus carota), peach (Prunus persica), perennial ryegrass (Lolium perenne), and bittersweet nightshade (Solanum dulcamara). Beneficial effects of AFPs have been reported for sheep, cattle, and buffalo bull sperm. ${ }^{44-48}$

\section{Oxidative stress}

Oxidative stress is one of the most important factors contributing to poor post-thaw semen quality during sperm cryopreservation. ${ }^{49}$ Oxidative stress arises due to an imbalance between the production of ROS and a biological system's ability to detoxify it that is, when oxidants exceed antioxidants. ${ }^{50}$ It is often associated with an increased rate of cellular damage induced by oxygen $\left(\mathrm{O}_{2}\right)$ and oxygenderived oxidants. ${ }^{51}$

ROS broadly is represented by radicals such as the hydroxyl ion, superoxide, nitric oxide, peroxyl ion, and nonradicals like peroxynitrate, ozone, nascent oxygen, and hydrogen peroxide. ${ }^{52}$ Two ROS-generating systems are possibly involved, that is, nicotinamide adenine dinucleotide phosphate (NADPH) oxidase at the level of sperm membrane $^{53}$ and sperm diaphorase (mitochondrial nicotinamide adenine dinucleotide-hydrogen, NADH-dependent oxidoreductase) at the level of mitochondria. ${ }^{54}$ In bovine semen, ROS are also generated by immature, dead, and defective spermatozoa through an aromatic amino acid oxidase pathway. ${ }^{55}$ Leucocytes and radiation exposure contribute in a minor way to the formation of ROS. ${ }^{56}$

\section{Inevitable fate of oxidative stress}

Freeze-thaw stress enhances the sperm respiration or oxidative metabolism and excess formed electrons instead of completing the whole series of the electron transport chain in mitochondria, directly leak through mitochondrial inner membrane, and bind with oxygen resulting in the formation of free-radical superoxide (highly reactive molecule). Although ROS formation takes place during the whole cryopreservation procedure, excessive production of ROS during the freeze-thaw process mainly inflicts oxidative damage. Due to their highly reactive nature, they can combine readily with other molecules, directly causing oxidation that can lead to structural and functional changes and finally cellular damage. ${ }^{57}$ All cellular components, including lipids, proteins, nucleic acids, and sugars are potential targets of oxidative stress. ${ }^{56}$

ROS produced during the freeze-thaw process cause lipid peroxidation of sperm plasma membrane, which leads to the formation of a number of toxic by-products such as malondialdehyde (MDA), conjugated dienes, and lipid 
hydroperoxides (4-hydroxynonenal, 4- HNE and various 2alkenals), which have damaging effects to the membrane system. ${ }^{52}$ They decrease membrane fluidity, electrical resistance, and change the phase properties of membranes. Peroxidative attack on polyunsaturated fatty acids causes both structural and functional damage that is, the membrane becomes fragile and its semipermeable property is lost leading to membrane leaching. Cholesterol efflux, calcium influx, capacitation, and acrosomal reaction-like changes cumulatively depict cryocapacitation, which reduces viability and sperm fertility. ${ }^{1}$ Membrane damage causes loss of adenosine triphosphate (ATP), proteins, and essential enzymes, which lead to reduction in motility of frozen-thawed spermatozoa. Toxic by-products also inhibit a large number of cellular enzymes such as glyceraldehyde 6-phosphate dehydrogenase (G-6-PDH) and adenosine triphosphatase (ATPase) that may also affect sperm movement. ${ }^{58}$

Addition of anti-PDC-109 protein in semen ejaculates ${ }^{59}$ and Met-anandamide (AEA) in freezing medium ${ }^{60}$ successfully reduced cryocapacitation-like changes in frozenthawed crossbred bull and ram spermatozoa, respectively, and thereby improved the post-thaw semen quality. Regucalcin (Senescence marker protein-30), a calcium-binding protein, also prevented cryocapacitation and played a cryoprotective role for buffalo bull spermatozoa. ${ }^{61}$ The characteristics of membranes that affect their sensitivity include the cholesterol/phospholipid ratio, degree of hydrocarbon chain saturation, and protein/phospholipid ratio. ${ }^{1}$

Along with plasma membrane damage, mitochondrial inner membrane and nuclear deoxyribonucleic acid (DNA) damage also occur due to ROS as these are more prone to oxidative damage. Sperm mitochondria are both the main source and target of $\operatorname{ROS}^{54,62}$ and have a role in many pathological implications of sperm cells. ${ }^{63}$ Mitochondria are more likely to sustain damage from oxidative attack because mitochondrial DNA (mt DNA) is a circular double-stranded DNA organized in nucleoids near the electron transport chain (ROS source) and lacks introns. ${ }^{64}$ DNA damage or mutation leads to defective protein formation during the process of transcription and translation, which affect spermatozoal metabolism. In humans, a level of $15 \%-25 \%$ spermatozoa with damaged DNA is considered to have reduced fertility, ${ }^{65,66}$ whereas bulls have been observed to have reduced fertility with over $10 \%$ damaged DNA spermatozoa. $^{67}$

\section{Strategies to combat oxidative stress}

Oxidative stress can be reduced either by neutralizing ROS, which are generated during semen cryopreservation process, or by minimizing the level of sources, which lead to ROS production (Fig. 1). Different strategies used to neutralize ROS, which are generated, are either addition of antioxidants or reductants (Fig. 1).

Antioxidants, in general, are the compounds and reactions which dispose, scavenge, suppress, or hinder the oxidative chain reaction in the formation of ROS, or oppose their actions. ${ }^{68}$ Enzymatic antioxidants (natural antioxidants) include superoxide dismutase (SOD), catalase, glutathione peroxidase (GPx), and glutathione reductase (GR). ${ }^{52}$ SOD dismutates superoxide anion $\left(\mathrm{O}_{2}^{-}\right)$and forms $\mathrm{O}_{2}$ and hydrogen peroxide $\left(\mathrm{H}_{2} \mathrm{O}_{2}\right)$; and catalase converts $\mathrm{H}_{2} \mathrm{O}_{2}$ to $\mathrm{O}_{2}$ and $\mathrm{H}_{2} \mathrm{O}{ }^{51}$ The catalase enzyme has been reported to be present in cattle and ram spermatozoa, which control the aging process in sperm cells due to oxidative stress. ${ }^{69}$ Addition of SOD and butylated hydroxytoluene to citrate-egg yolk extender caused the lowest production of MDA in frozen-thawed bovine semen. ${ }^{70}$ Sperm viability was comparatively higher in samples extended with $100 \mathrm{U}$ $\mathrm{GPx} / \mathrm{mL}{ }^{70}$

Nonenzymatic antioxidants, such as vitamin $\mathrm{C}$ and vitamin $E{ }^{71}$ ferrous sulfate and ascorbic acid, ${ }^{72}$ vitamin $B_{12}{ }^{73}$ astaxanthin, ${ }^{74}$ canthaxanthin, ${ }^{75}$ L-glutamine and L- proline ${ }^{76}$ inositol, $^{49}$ glutathione and cysteine, ${ }^{77}$ cysteine and taurine, ${ }^{55}$ methionine and raffinose, ${ }^{78}$ raffinose and hypotaurine, ${ }^{79}$ taurine and trehalose, ${ }^{69,80}$ trehalose and zinc sulfate, ${ }^{81}$ cysteamine and hyaluronan, ${ }^{69}$ manganese ion $\left(\mathrm{Mn}^{2+}\right),{ }^{82}$ coenzyme Q10 (CoQ10) and ellagic acid, ${ }^{83}$ melatonin, ${ }^{84}$ and IGF-I, ${ }^{85}$ have been successfully incorporated in semen extender to enhance the sperm cryosurvivability and post-thaw semen quality.

Some plant extracts having an antioxidant property such as pomegranate juice, ${ }^{86}$ Rhodiola sacra aqueous extract, ${ }^{87}$ Resveratrol, ${ }^{88}$ Persimmon (Diospyros kaki) fruit extract, ${ }^{89}$ Quercetin, ${ }^{90}$ Lycopene, ${ }^{77}$ Spirulina maxima extract, ${ }^{91}$ Rosemary (Rosmarinus officinalis) extract, ${ }^{92}$ Lycium barbar$u m$, and Laminaria japonica plant extract ${ }^{93}$ have been used in semen extenders to enhance post-thaw semen quality of mammalian species. El-Sheshtawy et al. ${ }^{94,95}$ concluded that pollen grains and honey improved preservability of bull semen due to its high content of antioxidants, flavonoids, vitamins, and organic acids. Supplementation of fresh bull semen with curcumin significantly increased the sperm content of GSH after thawing. ${ }^{96}$ Maca (Lepidium meyenii) root powders or alcoholic extracts appeared to improve semen characteristics in men. ${ }^{97}$ Plant extracts from African Guinea pepper (Xylopia aethiopica), Grape (Vitis vinifera) seed, and berry juices, which have a preservative effect, can be used as semen additives. ${ }^{98,99}$ Oleuropein, phenolic compound found in olives and olive oil, hydrolyzes to form hydroxytyrosol, which has potential antioxidant activity and may be used to improve semen quality. ${ }^{100}$ Propolis, a resinous substance from plants decreased the percentages of dead and abnormal spermatozoa and increased testosterone level in rats. ${ }^{101}$ Silymarin (milk thistle-Silybum marianum extract) as a natural additive to semen extenders improved preservability of frozen bull semen. ${ }^{102}$

These antioxidants are efficient and reported to improve the post-thaw semen quality upon supplementation. But, many of the antioxidants function or their mechanism of action at the cellular level are not clearly known that is, how they act and at which steps of ROS production or oxidative damage in sperm cells? Also, are pro-oxidant activities of these antioxidant radicals formed after scavenging ROS? This question requires a better understanding of the doseresponse relationship with respect to the efficacy and toxicity of antioxidants used for minimizing oxidative stress.

Reductants, such as the hydrogen molecule $\left(\mathrm{H}_{2}\right)$, can easily diffuse across membranes and can react with cytotoxic $\bullet \mathrm{OH}$ in all the organelles, including mitochondria and the nucleus, thus effectively protecting cells against oxidative damage. $\mathrm{H}_{2}$ also prevents a decrease in the cellular levels of ATP synthesized in mitochondria. ${ }^{103}$ The rate of forward motility was increased by $\mathrm{H}_{2}$ treatment in experimentally damaged sperm suspensions from human patients. $^{104}$ 


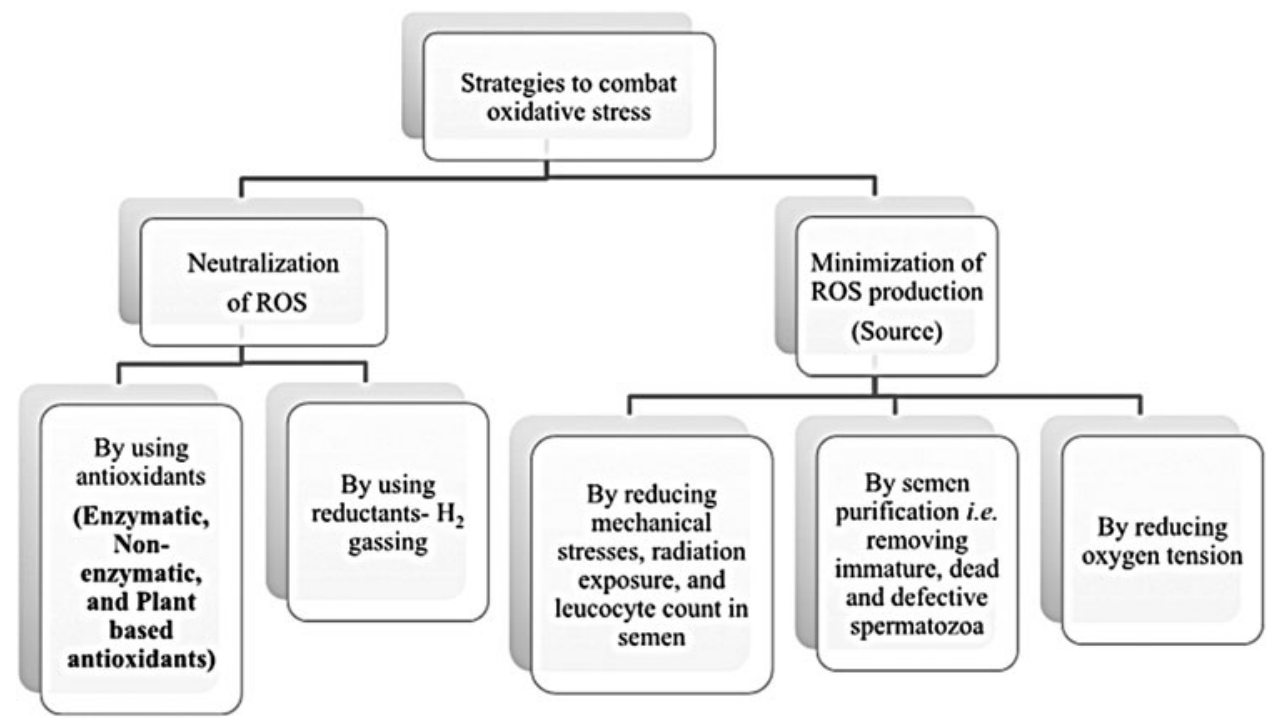

FIG. 1. Schematic diagram showing different strategies to combat oxidative stress.
The sources which lead to ROS production are radiation exposure, leucocytes, immature, defective, and dead spermatozoa; and oxygen tension present in microenvironment of spermatozoa (Fig. 1). Reducing the oxygen tension and minimizing the radiation exposure, leucocytes, dead and defective spermatozoa in the semen, and ROS production can be inhibited to a sufficiently low level (Fig. 1).

Radiation exposure should be minimized during transfer of semen from collection site to the laboratory and it should be built in a way to obviate direct exposure of sunlight during semen processing. Semen collection should be carried out from healthy, breedable bulls and not from diseased animals to minimize leucocyte count in semen and preputial washing should be done at regular intervals that is, 10 days or according to protocol followed at different semen stations. The bulls managed at a semen station should go through periodical testing and vaccinations as per the minimum standard protocol. Bulls should be tested against tuberculosis, Johne's disease, brucellosis, campylobacteriosis, trichomoniasis, and vaccinated against foot and mouth disease, hemorrhagic septicemia, black quarter, theileriosis and anthrax. However, vaccinations against bacterial diseases should be done only if there is an outbreak or prevalence of a particular disease in that particular area.

Methods of semen purification that is, removal of immature, dead, and defective spermatozoa are based on swimup technique, Percoll density gradient centrifugation, Ficoll wash, glass wool-Sephadex (GWS) filtration, magnetic bead separation [magnetic-activated cell sorting (MACS) technique], and nanoparticle separation (semen nanopurification). Recovery of spermatozoa is based on sperm motility in overlaid media against the gravitational force (sperm swim-up), while recovery of spermatozoa by gradient centrifugation (Percoll) is based on separation of defective sperm as they were not able to pass through a layer of colloid during centrifugation. ${ }^{105}$ Nowadays, PureSperm and OptiPrep have replaced Percoll in human IVF as these are optimized sperm gradient media and more effective in separation of damaged sperm. ${ }^{106}$ Ficoll wash is an alternative to Percoll gradient centrifugation in livestock species. $^{107}$
Clusterin (CLU) from seminal plasma has affinity toward defective spermatozoa, therefore, CLU-positive frozenthawed bull spermatozoa were retained in glass wool during GWS filtration, which improved the overall semen quality. ${ }^{108}$ Leukosorb filters also served the same purpose as GWS for the removal of defective spermatozoa from stallion semen. ${ }^{109}$ In MACS, magnetic beads conjugated with Annexin $\mathrm{V}$ bind to sperm with damaged plasma membranes, allowing for their depletion by a magnet. ${ }^{110}$ Within livestock species, MACS was successfully applied to improve post-thaw motility of bull spermatozoa. ${ }^{111}$

Semen nanopurification, a nanoparticle-based magnetic purification method, was developed to remove damaged or defective spermatozoa. Two types of iron oxide nanoparticles that is, particles coated with antibody against ubiquitin (present on the surface of defective spermatozoa), and particles coated with the lectin (peanut agglutinin) PNA (bind to glycans exposed by acrosomal damage in defective spermatozoa) were used for nanopurification of bull semen. ${ }^{112}$ This approach enhanced bull semen quality before semen cryopreservation. A comparative efficacy of the nanotechnique with respect to the swim up technique for the purification of buffalo bull spermatozoa has recently been reported from our laboratory. ${ }^{113}$ Nowadays, nanoparticles coated with antibody against damaged DNA and mitochondria are also being used in nanopurification of semen.

In these methods described for semen purification, the recovery rate of sperm is low in most of them as live or normal sperm also gets trapped along with dead and defective sperm during execution of these methods. Dead and defective sperm are low in good-quality semen; therefore, these techniques cannot be solely implied to improve the post-thaw semen quality as ROS produced due to cryopreservation stress cannot be minimized effectively. Some are not suitable for routine use in semen collection and cryopreservation due to cost, labor intensity, procedural time lags, and expensive equipment.

A novel approach for minimizing oxidative stress is to reduce the oxygen tension in sperm microenvironment as a number of literature pointed out a direct link of $\mathrm{O}_{2}$ with ROS production. In 1943, MacLeod ${ }^{114}$ documented the 
toxicity of oxygen on human spermatozoa. The rate of lipid peroxidation and subsequent motility loss in sperm are linear functions of the partial pressure of $\mathrm{O}_{2}$ in the medium. ${ }^{115}$ During the freezing-thawing process, semen is exposed to atmospheric oxygen, which in turn increases the ROS production and lipid peroxidation. ${ }^{116}$ Because of the principal role of $\mathrm{O}_{2}$ in the formation of ROS, post-thaw sperm quality can be improved if the cryopreservation procedure is carried out under anaerobic conditions. ${ }^{117}$

To achieve low $\mathrm{O}_{2}$ tension, Darr et al. and London et al. ${ }^{64,118}$ incorporated a commercially available Escherichia coli membrane preparation that is, Oxyrase, in the cryomedium, which improved post-thaw semen qualities of the stallion. It is a bacterial electron transport system that in the presence of a suitable hydrogen donor (i.e., lactate), decreases $\mathrm{O}_{2}$ level in cryomedia. ${ }^{119}$ These bacterial electron transport chains (Oxyrase) act as acceptors for the excess electrons formed due to increased sperm metabolism as a result of freeze-thaw stress, to finally form harmless $\mathrm{H}_{2} \mathrm{O}$ instead of harmful $\mathrm{O}_{2}{ }^{-}$. The use of Oxyrase, and a mitochondrial uncoupler $(2,4$-dinitrophenol) has been shown to reduce oxidative damage and improved the post-thaw semen quality of rhesus monkey. ${ }^{120}$

Oxygen tension in the sperm microenvironment that is, extender, can also be reduced by partial deoxygenation process. In successive years, partial removal of oxygen from semen extender has been carried out using different approaches as reported from our laboratory that is, through flash-frozen/freeze-pump thaw cycle process using $\mathrm{LN}_{2}$, through a $\mathrm{N}_{2}$ gassing process/2-3 bubbles per second using gaseous $\mathrm{N}_{2}$ and through applying negative pressure to the diluent using modified vacuum pump. A flash-freezing process was used to degasify semen extender, which gave better results in semen quality parameters at post-thaw stage. ${ }^{121}$ Balamurugan et al. ${ }^{122}$ compared both the $\mathrm{LN}_{2}$ freezing method (by flash-freezing process) and mechanical method (by applying negative pressure) with that of a control to observe their effects on post-thaw semen quality of buffalo bull. But in both these methods, the dissolved oxygen (D.O.) in extender was not maintained at a desired level to observe its effect and to determine optimum oxygen level indicating better semen freezability. Therefore, we used the $\mathrm{N}_{2}$ gassing method and D.O. concentration was recorded with the help of a D.O. meter, before and after $\mathrm{N}_{2}$ gassing for varied time intervals. ${ }^{123}$

Nitrogen gassing has been reported to improve the storage efficiency of Caprogen diluent at room temperature or at $5^{\circ} \mathrm{C} .{ }^{124,125}$ Storage of diluted semen under $\mathrm{N}_{2}$ gas reduces the oxygen tension as well as metabolic activity of spermatozoa without affecting the $\mathrm{pH}$ of the medium. ${ }^{125}$ Verberckmoes et al. ${ }^{126}$ documented that storage of bovine liquid semen for up to 3 days in Caprogen diluent enables a 10-fold reduction in insemination dose without affecting sperm fertility. However, what is the D.O. concentration in normally used extender and how much $\mathrm{N}_{2}$ gassing should be done to displace oxygen to optimize the post-thaw semen quality? What should be the minimum D.O. concentration in semen extender essential for spermatozoa survival and metabolism? These were research gaps. The Egg Yolk-TrisGlycerol (EYTG) extender kept in a water bath $\left(35^{\circ} \mathrm{C}\right)$ had a D.O. concentration of $11.7 \mathrm{ppm}$ (11-12 ppm), and it required $\mathrm{N}_{2}$ gassing for 16 and 9 minutes at 2-3 bubbles/sec to achieve D.O. concentration of $\sim 4$ and $8 \mathrm{ppm}$, respective- ly. ${ }^{123}$ The semen extender having $4 \mathrm{ppm}$ of D.O. showed better post-thaw semen quality followed by 8 ppm. ${ }^{127,128}$ Adequate D.O. concentration in semen extender for spermatozoan survival and metabolism is $4-8 \mathrm{ppm}$, or more precisely $4 \mathrm{ppm}$ as post-thaw semen quality was very poor in 2 ppm group. 128

In these methods of partial deoxygenation, approaches were used to minimize ROS production, but free radicals already present in the semen could not be effectively removed, which might affect the post-thaw semen quality. However, a procedural time lag of deoxygenation was also a limiting factor in the early processing of semen for cryopreservation. The techniques of quicker deoxygenation of the extender up to a desired dissolved $\mathrm{O}_{2}$ concentration would have shortened the processing time. When compared with other strategies, partial deoxygenation of semen extender with $\mathrm{N}_{2}$ gassing is a cost-effective, comparatively easy, and a potential approach to large-scale frozen semen production.

\section{Conclusion}

Advances in sperm cryopreservation techniques have taken place over time, and the directional freezing technique and sperm vitrification were proposed, as these techniques were found to be superior to conventional freezing in straws. However, conventional freezing techniques are still the most commonly used worldwide for semen cryopreservation of domestic species. During conventional cryopreservation, freeze-thaw damage occurs due to heterogeneous ice nucleation and ice recrystallization. To minimize these damages, AFPs were added in semen extender and beneficial effects were observed in terms of semen quality parameters. Apart from this, spermatozoa experience temperature stress (cold shock) and mainly oxidative stress during the whole cryopreservation process, which leads to structural and functional damages to sperm. One way to increase membrane fluidity and to prevent cold shock and cryocapacitation-like changes is the addition of cholesterol to the membrane in the form of CLC. Oxidative stress can be minimized either by neutralizing ROS through enzymatic, nonenzymatic, plant-based antioxidants or reductants; or by minimizing the level of sources like radiation exposure, leucocytes, and dead and defective spermatozoa, which lead to ROS production during the semen cryopreservation process. A novel approach of minimizing oxidative stress is the partial deoxygenation of semen extender to reduce the oxygen tension in sperm microenvironment. It is the process in which partial removal of oxygen from the extender is carried out through a flashfreezing process using $\mathrm{LN}_{2}, \mathrm{~N}_{2}$ bubbling/gassing process, or applying negative pressure to the diluent using a modified vacuum pump. When compared with other strategies, partial deoxygenation of semen extender with $\mathrm{N}_{2}$ gassing has been found to be cost effective, comparatively easy, and a potential approach to large-scale frozen semen production.

\section{Author Disclosure Statement}

No conflicting financial interests exist.

\section{References}

1. Medeiros CM, Forell F, Oliveira AT, Rodrigues JL. Current status of sperm cryopreservation: Why isn't it better? Theriogenology 2002;57:327-344. 
2. Curry MR. Cryopreservation of semen from domestic livestock. Rev Reprod 2000;5:46-52.

3. Lessard C, Parent S, Leclerc P, Baileys JL, Sullivan R. Cryopreservation alters the levels of the bull sperm surface protein P25b. J Androl 2000;21:700-707.

4. Roussel JD, Kellgren HC, Patrick TE. Bovine semen frozen in liquid nitrogen vapor. J Dairy Sci 1964;47:14031406.

5. Barbas JP, Mascarenhas RD. Cryopreservation of domestic animal sperm cells. Cell Tissue Banking 2009;10: 49-62.

6. Gao D, Critser JK. Mechanisms of cryoinjury in living cells. ILAR J 2000;41:187-196.

7. Yeste M. Sperm cryopreservation update: Cryodamage, markers, and factors affecting the sperm freezability in pigs. Theriogenology 2016;85:47-64.

8. Arav A. Device and methods for multigradient directional cooling and warming of biological samples. US Patent $5,873,254$. Interface Multigrad Technology, United States, 1999.

9. Saragusty J, Osmers JH, Hildebrandt TB. Controlled ice nucleation-Is it really needed for large-volume sperm cryopreservation?. Theriogenology 2016;85:1328-1333.

10. Saragusty J, Gacitua H, Zeron Y, Rozenboim I, Arav A. Double freezing of bovine semen. Anim Reprod Sci 2009; 115:10-17.

11. Arav A, Saragusty J. Directional freezing of sperm and associated derived technologies. Anim Reprod Sci 2016; 169:6-13.

12. Arav A, Yavin S, Zeron Y, Natan D, Dekel I, Gacitua H. New trends in gamete's cryopreservation. Mol Cell Endocrinol 2002;187:77-81.

13. Hayakawa H, Yamazaki T, Oshi M, Hoshino M, Dochi O, Koyama H. Cryopreservation of conventional and sexsorted bull sperm using a directional freezing method. Reprod Fertil Dev 2007;19:176-177.

14. Saragusty J, Gacitua H, Pettit MT, Arav A. Directional freezing of equine semen in large volumes. Reprod Domest Anim 2007;42:610-615.

15. Reid CE, Hermes R, Blottner S, et al. Split-sample comparison of directional and liquid nitrogen vapour freezing method on post-thaw semen quality in white rhinoceroses (Ceratotherium simum simum and Ceratotherium simum cottoni). Theriogenology 2009;71:275-291.

16. Saragusty J, Hildebrandt TB, Behr B, Knieriem A, Kruse J, Hermes R. Successful cryopreservation of Asian elephant (Elephas maximus) spermatozoa. Anim Reprod Sci 2009;115:255-266.

17. Zheng H, Li B, Yang SH, Chen LL, He BL, Jiao JL. Cryopresevation of sperms with directional freezing method in Yunnan Diannan miniature pig. Chin J Lab Anim Sci 2010;6:61-65.

18. Luyet BJ, Hodapp EL. Revival of frog's spermatozoa vitrified in liquid air. Proc Soc Exp Biol Med 1938;39: 433-434.

19. Rall WF, Fahy GM. Ice-free cryopreservation of mouse embryos at $-196^{\circ} \mathrm{C}$ by vitrification. Nature $1985 ; 313: 573-$ 575.

20. Vajta G, Holm P, Greve T, Callesen H. Vitrification of porcine embryos using the open pulled straw (OPS) method. Acta Vet Scand 1997;38:349-352.

21. Vajta G, Holm P, Kuwayama M, et al. Open pulled straw (OPS) vitrification: A new way to reduce cryoinjuries of bovine ova and embryos. Mol Reprod Dev 1998;51: 53-58.
22. Matsumoto H, Jiang JY, Tanaka T, Sasada H, Sato E. Vitrification of large quantities of immature bovine oocytes using nylon mesh. Cryobiology 2001;42:139-144.

23. Isachenko $\mathrm{V}$, Isachenko $\mathrm{E}$, Katkov II, et al. Cryoprotectant-free cryopreservation of human spermatozoa by vitrification and freezing in vapor: Effect on motility, DNA integrity, and fertilization ability. Biol Reprod 2004;71:1167-1173.

24. Mohamed MS. Slow cryopreservation is not superior to vitrification in human spermatozoa; an experimental controlled study. Iranian J Reprod Med 2015;13:633.

25. Nawroth F, Isachenko V, Dessole $S$, et al. Vitrification of human spermatozoa without cryoprotectants. CryoLetters 2002;23:93-102.

26. Isachenko V, Isachenko E, Montag M, et al. Clean technique for cryoprotectant-free vitrification of human spermatozoa. Reprod Biomed Online 2005;10:350-354.

27. Isachenko V, Rahimi G, Mallmann P, Sanchez R, Isachenko E. Technologies of cryoprotectant-free vitrification of human spermatozoa: Asepticity as criterion of effectiveness. Andrology 2017;5:1055-1063.

28. Isachenko E, Mallmann P, Rahimi G, et al. Vitrification technique-new possibilities for male gamete lowtemperature storage. In: Katkov II (ed). Current Frontiers in Cryobiology. ISBN: 978-953-51-0191-8. Croatia: IntechOpen, 2012:41-76.

29. Sánchez R, Risopatrón J, Schulz M, et al. Canine sperm vitrification with sucrose: Effect on sperm function. Andrologia 2011;43:233-241.

30. Vizuete G, Jiménez E, Agüera EI, Pérez-Marín CC. Impact of ultra-rapid freezing on the motility, morphology, viability and acrosome integrity of epididymal cat sperm diluted in sucrose-based extenders. Reprod Domest Anim 2014;49:e5-e8.

31. Jiménez-Rabadán P, García-Álvarez O, Vidal A, et al. Effects of vitrification on ram spermatozoa using free-egg yolk extenders. Cryobiology 2015;71:85-90.

32. Arando A, Gonzalez A, Delgado JV, Arrebola FA, PerezMarín CC. Storage temperature and sucrose concentrations affect ram sperm quality after vitrification. Anim Reprod Sci 2017;181:175-185.

33. Watson PF. The effects of cold shock on sperm cell membranes. In: Morris G.J. and Clarke A (eds). Effects of Low Temperatures on Biological Membranes. London: Academic Press, 1981:189-218.

34. Drobnis EZ, Crowe LM, Berger T, Anchordoguy TJ, et al. Cold shock damage is due to lipid phase transitions in cell membranes: A demonstration using sperm as a model. J Exp Zool 1993;265:432-437.

35. Holt WV, North RD. Partially irreversible cold-induced lipid phase transitions in mammalian sperm plasma membrane domains: Freeze-fracture study. J Exp Zool 1984;230:473-483.

36. De Leeuw FE, Chen HC, Colenbrander B, Verkleij AJ. Cold-induced ultrastructural changes in bull and boar sperm plasma membranes. Cryobiology 1990;27:171-183.

37. Purdy PH, Graham JK. Effect of adding cholesterol to bull sperm membranes on sperm capacitation, the acrosome reaction, and fertility. Biol Reprod 2004;71:522-527.

38. Rajoriya JS, Prasad JK, Ramteke SS, et al. Enriching membrane cholesterol improves stability and cryosurvival of buffalo spermatozoa. Anim Reprod Sci 2016;164:72-81.

39. Mocé E, Purdy PH, Graham JK. Treating ram sperm with cholesterol-loaded cyclodextrins improves cryosurvival. Anim Reprod Sci 2010;118:236-247. 
40. Moore AI, Squires EL, Graham JK. Adding cholesterol to the stallion sperm plasma membrane improves cryosurvival. Cryobiology 2005;51:241-249.

41. Galantino-Homer HL, Zeng WX, Megee SO, Dallmeyer M, Voelkl D, Dobrinski I. Effects of 2-hydroxypropyl- $\beta$ cyclodextrin and cholesterol on porcine sperm viability and capacitation status following cold shock or incubation. Mol Reprod Dev 2006;73:638-650.

42. Gao DY, Ashworth E, Watson PF, Kleinhans FW, Mazur $\mathrm{P}$, Critser JK. Hyperosmotic tolerance of human spermatozoa: Separate effects of glycerol, sodium chloride, and sucrose on spermolysis. Biol Reprod 1993;49:112-123.

43. Watson PF, Duncan AE. Effect of salt concentration and unfrozen water fraction on the viability of slowly frozen ram spermatozoa. Cryobiology 1988;25:131-142.

44. Payne SR, Oliver JE, Upreti GC. Effect of antifreeze proteins on the motility of ram spermatozoa. Cryobiology 1994;31:180-184.

45. Prathalingam NS, Holt WV, Revell SG, Mirczuk S, Fleck RA, Watson PF. Impact of antifreeze proteins and antifreeze glycoproteins on bovine sperm during freeze-thaw. Theriogenology 2006;66:1894-1900.

46. Qadeer S, Khan MA, Ansari MS, et al. Evaluation of antifreeze protein III for cryopreservation of Nili-Ravi (Bubalus bubalis) buffalo bull sperm. Anim Reprod Sci 2014;148:26-31.

47. Qadeer S, Khan MA, Ansari MS, et al. Efficiency of antifreeze glycoproteins for cryopreservation of Nili-Ravi (Bubalus bubalis) buffalo bull sperm. Anim Reprod Sci 2015;157:56-62.

48. Qadeer S, Khan MA, Shahzad Q, et al. Efficiency of beetle (Dendroides canadensis) recombinant antifreeze protein for buffalo semen freezability and fertility. Theriogenology 2016;86:1662-1669.

49. Bucak MN, Tuncer PB, Sarı̈zkan S, et al. Effects of antioxidants on post-thawed bovine sperm and oxidative stress parameters: Antioxidants protect DNA integrity against cryodamage. Cryobiology 2010;61:248-253.

50. Du Plessis SS, Makker K, Desai NR, Agarwal A. Impact of oxidative stress on IVF. Expert Rev Obstet Gynecol 2008;3:539-554.

51. Sikka SC. Oxidative stress and role of antioxidants in normal and abnormal sperm function. Front Biosci 1996; 1:e78-e86.

52. Bansal AK, Bilaspuri GS. Impacts of oxidative stress and antioxidants on semen functions. Vet Med Int 2011;2011. Article ID 686137.

53. O'flaherty C, Beorlegui N, Beconi MT. Participation of superoxide anion in the capacitation of cryopreserved bovine sperm. Int J Androl 2003;26:109-114.

54. Koppers AJ, De Iuliis GN, Finnie JM, McLaughlin EA, Aitken RJ. Significance of mitochondrial reactive oxygen species in the generation of oxidative stress in spermatozoa. J Clin Endocrinol Metab 2008;93:3199-3207.

55. Sarı̈̈zkan S, Bucak MN, Tuncer PB, Ulutaş PA, Bilgen A. The influence of cysteine and taurine on microscopicoxidative stress parameters and fertilizing ability of bull semen following cryopreservation. Cryobiology 2009;58: 134-138.

56. Agarwal A, Makker K, Sharma R. Clinical relevance of oxidative stress in male factor infertility: An update. Am J Reprod Immunol 2008;59:2-11.

57. Guerin P, El Mouatassim S, Menezo Y. Oxidative stress and protection against reactive oxygen species in the pre- implantation embryo and its surroundings. Hum Reprod Update 2001;7:175-189.

58. Pereira R, Sá R, Barros A, Sousa M. Major regulatory mechanisms involved in sperm motility. Asian J Androl 2017;19:5.

59. Srivastava N, Srivastava SK, Ghosh SK, Singh LP, Prasad JK, et al. Sequestration of PDC-109 protein improves freezability of crossbred bull spermatozoa. Anim Reprod Sci 2012;131:54-62.

60. Talebiyan R, Amidi F, Samini M, Mirshokraei P, Dehkordi SH. Effect of met-anandamide on prevention of hyperactivation, cryo-capacitation and acrosome reaction in ram semen cryopreservation. Kafkas Univ Veteriner Fak Derg 2015;21:545-551.

61. Pillai H, Parmar MS, Shende AM, et al. Effect of supplementation of recombinant Regucalcin in extender on cryopreservation of spermatozoa of water buffalo (Bubalus bubalis). Mol Reprod Dev 2017;84:1133-1139.

62. Moraes CR, Meyers S. The sperm mitochondrion: Organelle of many functions. Anim Reprod Sci 2018;194: 71-80.

63. Pena FJ, Rodríguez Martínez H, Tapia JA, Ortega Ferrusola C, Gonzalez Fernandez L, Macias Garcia B. Mitochondria in mammalian sperm physiology and pathology: A review. Reprod Domest Anim 2009;44:345349.

64. Darr C, Martorana K, Scanlan T, Meyers S. The effect of low oxygen during the early phases of sperm freezing in stallions with low progressive motility: Can we improve post-thaw motility of stallion sperm? J Equine Vet Sci 2016;42:44-51.

65. Evenson DP, Jost LK, Marshall D, et al. Utility of the sperm chromatin structure assay as a diagnostic and prognostic tool in the human fertility clinic. Hum Reprod 1999;14:1039-1049.

66. Evenson DP, Jost LK, Corzett M, Balhorn R. Characteristics of human sperm chromatin structure following an episode of influenza and high fever: A case study. J Androl 2000;21:739-746.

67. Bochenek M, Smorag Z, Pilch J. Sperm chromatin structure assay of bulls qualified for artificial insemination. Theriogenology 2001;56:557-567.

68. Miller JK, Brzezinska-Slebodzinska E, Madsen FC. Oxidative stress, antioxidants, and animal function. J Dairy Sci 1993;76:2812-2823.

69. Bucak MN, Ateşşahin A, Varışlı Ö, Yüce A, Tekin N, Akçay A. The influence of trehalose, taurine, cysteamine and hyaluronan on ram semen: Microscopic and oxidative stress parameters after freeze-thawing process. Theriogenology 2007;67:1060-1067.

70. Asadpour R, Jafari R, Tayefi-Nasrabadi H. The effect of antioxidant supplementation in semen extenders on semen quality and lipid peroxidation of chilled bull spermatozoa. Iranian J Vet Res 2012;13:40.

71. Mittal PK, Anand M, Madan AK, Yadav S, Kumar J. Antioxidative capacity of vitamin E, vitamin $\mathrm{C}$ and their combination in cryopreserved Bhadavari bull semen. Vet World 2014;7:1127-1131.

72. Bansal AK, Bilaspuri GS. Effect of ferrous sulphate and ascorbic acid on motility, viability and lipid peroxidation of crossbred cattle bull spermatozoa. Animal 2008;2:100104.

73. Hu JH, Tian WQ, Zhao XL, Zan LS, Xin YP, Li QW. The cryoprotective effects of vitamin $\mathrm{B}_{12}$ supplementation on 
bovine semen quality. Reprod Domest Anim 2011;46: 66-73.

74. Lee E, Kim D. Effects of Astaxanthin on Miniature Pig Sperm Cryopreservation. BioMed Res Int 2018;2018. Article ID 6784591.

75. Souza HM, Arruda LC, Monteiro MM, et al. The effect of canthaxanthin on the quality of frozen ram spermatozoa. Biopreservation Biobanking 2017; 15:220-227.

76. Bucak MN, Tuncer PB, Sarıözkan S, Ulutaş PA. Comparison of the effects of glutamine and an amino acid solution on post-thawed ram sperm parameters, lipid peroxidation and anti-oxidant activities. Small Ruminant Res 2009;81:13-17.

77. Uysal O, Bucak MN. Effects of oxidized glutathione, bovine serum albumin, cysteine and lycopene on the quality of frozen-thawed ram semen. Acta Vet Brno 2007; 76:383-390.

78. Tuncer PB, Bucak MN, Sarı̈zkan S, et al. The effect of raffinose and methionine on frozen/thawed Angora buck (Capra hircus ancryrensis) semen quality, lipid peroxidation and antioxidant enzyme activities. Cryobiology 2010;61:89-93.

79. Bucak MN, Keskin N, Taşpınar M, et al. Raffinose and hypotaurine improve the post-thawed Merino ram sperm parameters. Cryobiology 2013;67:34-39.

80. Reddy NS, Mohanarao GJ, Atreja SK. Effects of adding taurine and trehalose to a tris-based egg yolk extender on buffalo (Bubalus bubalis) sperm quality following cryopreservation. Anim Reprod Sci 2010;119:183-190.

81. Ghallab AM, Shahat AM, Fadl AM, Ayoub MM, Moawad AR. Impact of supplementation of semen extender with antioxidants on the quality of chilled or cryopreserved Arabian stallion spermatozoa. Cryobiology 2017;79: 14-20.

82. Bansal AK, Bilaspuri GS. Effect of manganese on bovine sperm motility, viability, and lipid peroxidation in vitro. Anim Reprod 2008;5:90-96.

83. Daghigh-Kia H, Blooki Z, Vaseghi Dodran H, Mahdipour M. Effect of adding coenzyme Q10 and Ellagic acid during cryopreservation on post-thaw quality of ram semen. Iranian J Appl Anim Sci 2017;7:445-451.

84. Ashrafi I, Kohram H, Ardabili FF. Antioxidative effects of melatonin on kinetics, microscopic and oxidative parameters of cryopreserved bull spermatozoa. Anim Reprod Sci 2013;139:25-30.

85. Selvaraju S, Krishnan BB, Archana SS, Ravindra JP. IGF1 stabilizes sperm membrane proteins to reduce cryoinjury and maintain post-thaw sperm motility in buffalo (Bubalus bubalis) spermatozoa. Cryobiology 2016;73:55-62.

86. El-Sheshtawy RI, Gamal A, El-Nattat WS. Effects of pomegranate juice in Tris-based extender on cattle semen quality after chilling and cryopreservation. Asian Pac J Reprod 2016;5:335-339.

87. Zhao HW, Li QW, Ning GZ, Han ZS, Jiang ZL, Duan YF. Rhodiola sacra aqueous extract (RSAE) improves biochemical and sperm characteristics in cryopreserved boar semen. Theriogenology 2009;71:849-857.

88. Sarlos P, Molnar A, Kokai M, Gabor G, Ratky J. Comparative evaluation of the effect of antioxidants in the conservation of ram semen. Acta Vet Hung 2002;50:235245.

89. El-Sheshtawy RI, El-Nattat WS. Effect of Diospyros kaki enriched extender on cattle bull sperm parameters and conception rate. Asian Pac J Reprod 2017;6:128.
90. Gibb Z, Butler TJ, Morris LH, Maxwell WM, Grupen CG. Quercetin improves the post-thaw characteristics of cryopreserved sex-sorted and non-sorted stallion sperm. Theriogenology 2013;79:1001-1009.

91. Mizera A, Kuczaj M, Szul A. Impact of the Spirulina maxima extract addition to semen extender on bovine sperm quality. Italian J Anim Sci 2019;18:601-607.

92. Daghigh-Kia H, Olfati-Karaji R, Hoseinkhani A, Ashrafi I. Effect of rosemary (Rosmarinus officinalis) extracts and glutathione antioxidants on bull semen quality after cryopreservation. Spanish J Agric Res 2014;12:98-105.

93. Ren F, Fang Q, Feng T, Li Y, Wang Y, et al. Lycium barbarum and Laminaria japonica polysaccharides improve Cashmere goat sperm quality and fertility rate after cryopreservation. Theriogenology 2019;129:29-36.

94. El-Sheshtawy RI, El-Nattat WS, Ali AH, Sabra HA. The Effect of Phoenix dactylifera pollen grains tris-infusion on semen preservability of local bull breeds. Glob Vet 2014; 13:728-732.

95. El-Sheshtawy RI, El-Nattat WS, Sabra HA, Ali AH. Effect of honey solution on semen preservability of local breeds of cattle bulls. World Appl Sci J 2014;32:20762078.

96. Bucak MN, Basspınar N, Tuncer PB, et al. Effects of curcumin and dithioerythritol on frozen-thawed bovine semen. Andrologia 2012;44:102-109.

97. Gonzales GF, Cordova A, Gonzales C, Chung A, Vega K, Villena A. Lepidium meyenii (Maca) improved semen parameters in adult men. Asian J Androl 2001;3:301-303.

98. Adaramoye OA, Adedara IA, Popoola B, Farombi EO. Extract of Xylopia aethiopica (Annonaceae) protects against gamma radiation induced testicular damage in Wistar rats. J Basic Clin Physiol Pharmacol 2010;21:295313.

99. Clement C, Witschi U, Kreuzer M. The potential influence of plant-based feed supplements on sperm quantity and quality in livestock: A review. Anim Reprod Sci 2012; 132:1-10.

100. Balaganur K, Srivastava SK, Davendra K, et al. Effect of hydroxytyrosol on sperm post-thaw motion and velocity of cryopreserved ram semen. Indian J Small Ruminants 2018;24:75-79.

101. Fonseca YM, Marquele-Oliveira F, Vicentini FT, et al. Evaluation of the potential of Brazilian propolis against UV-induced oxidative stress. Evid Based Complement Altern Med 2011;2011:8.

102. El-Sheshtawy RI, El-Nattat WS. Impact of Silymarin enriched semen extender on bull sperm preservability. Asian Pac J Reprod 2017;6:81.

103. Ohsawa I, Ishikawa M, Takahashi K, et al. Hydrogen acts as a therapeutic antioxidant by selectively reducing cytotoxic oxygen radicals. Nat Med 2007;13:688-694.

104. Nakata K, Yamashita N, Noda Y, Ohsawa I. Stimulation of human damaged sperm motility with hydrogen molecule. Med Gas Res 2015;5:2.

105. Oshio S. Apparent densities of spermatozoa of various mammalian species. Gamete Res 1988;20:159-164.

106. Claassens OE, Menkveld R, Harrison KL. Evaluation of three substitutes for Percoll in sperm isolation by density gradient centrifugation. Hum Reprod 1998;13:3139-3143.

107. Petruska P, Capcarova M, Sutovsky P. Antioxidant supplementation and purification of semen for improved artificial insemination in livestock species. Turk J Vet Anim Sci 2014;38643-652. 
108. Arzondo MM, Caballero JN, Marin-Briggiler CI, Dalvit G, Cetica PD, Vazquez-Levin MH. Glass wool filtration of bull cryopreserved semen: A rapid and effective method to obtain a high percentage of functional sperm. Theriogenology 2012;78:201-209.

109. Sieme H, Martinsson G, Rauterberg H, et al. Application of techniques for sperm selection in fresh and frozen-thawed stallion semen. Reprod Domest Anim 2003;38:134-140.

110. Paasch U, Grunewald S, Wuendrich K, Jope T, Glander HJ. Immunomagnetic removal of cryo-damaged human spermatozoa. Asian J Androl 2005;7:61-69.

111. Faezah SS, Zuraina FM, Farah JH, et al. The effects of magnetic separation on cryopreserved bovine spermatozoa motility, viability and cryo-capacitation status. Zygote 2014;22:378-386.

112. Odhiambo JF, DeJarnette JM, Geary TW, et al. Increased conception rates in beef cattle inseminated with nanopurified bull semen. Biol Reprod 2014;91:97-1.

113. Din O, Mustapha AR, Amin BY, et al. Comparative efficacy of enrichment of spermatozoa using swim up vis-à-vis nanotechnique in buffalo bull. Ruminant Sci 2018;7:73-76.

114. MacLeod J. The role of oxygen in the metabolism and motility of human spermatozoa. Am J Physiol 1943;138: 512-518.

115. Alvarez JG, Storey BT. Spontaneous lipid-peroxidation in rabbit and mouse epididymal spermatozoa dependence of rate on temperature and oxygen concentration. Biol Reprod 1985;32:342-351.

116. Bucak MN, Ateşşahin A, Yüce A. Effect of anti-oxidants and oxidative stress parameters on ram semen after the freeze-thawing process. Small Ruminant Res 2008;75: 128-134.

117. Gibb Z, Lambourne SR, Aitken RJ. The paradoxical relationship between stallion fertility and oxidative stress. Biol Reprod 2014;91:77.

118. London KT, Christensen BW, Scott CJ, et al. The effects of an oxygen scavenger and coconut water on equine sperm cryopreservation. J Equine Vet Sci 2017;58:51-57.

119. Adler HI. The use of microbial membranes to achieve anaerobiosis. Critic Rev Biotechnol 1990;10:119-127.

120. Dong Q, Tollner TL, Rodenburg SE, Hill DL, VandeVoort CA. Antioxidants, Oxyrase, and mitochondrial uncoupler 2, 4-dinitrophenol improved post thaw survival of rhesus monkey sperm from ejaculates with low cryosurvival Fertil Steril 2010;94:2359-2361.

121. Pande M, Srivastava N, Rajoriya JS, Ghosh SK, Prasad JK, Ramteke SS. Effects of degasified extender on quality parameters of cryopreserved bull spermatozoa. Int J Vet Sci Res 2015;1:70-78.

122. Balamurugan B, Ghosh SK, Lone SA, et al. Partial deoxygenation of extender improves sperm quality, reduces lipid peroxidation and reactive oxygen species during cryopreservation of buffalo (Bubalus bubalis) semen. Anim Reprod Sci 2018;189:60-68.

123. Kumar A, Prasad JK, Mustapha AR, et al. Effect of optimization of the levels of dissolved oxygen in semen extender on physico-morphological attributes and functional membrane integrity of crossbred bull spermatozoa. Indian J Anim Res 2018;53:704-710.

124. Shannon P. The effect of diluents containing glycine and glycine and glycerol, on the fertility of diluted bovine semen. N Z J Agric Res 1964;7:357-363.

125. Shannon P, Curson B. Effect of storage temperature on the viability and fertility of bovine sperm diluted and stored in Caprogen. N Z J Agric Res 1984;27:173-177.

126. Verberckmoes S, Van Soom A, Dewulf J, de Kruif A. Comparison of three diluents for the storage of fresh bovine semen. Theriogenology 2005;63:912-922.

127. Kumar A, Prasad JK, Mustapha AR, et al. Reduction of dissolved oxygen in semen extender with nitrogen gassing reduces oxidative stress and improves post-thaw semen quality of bulls. Anim Reprod Sci 2018;197:162-169.

128. Amin BY, Prasad JK, Ghosh SK, et al. Effect of various levels of dissolved oxygen on reactive oxygen species and cryocapacitation-like changes in bull sperm. Reprod Domest Anim 2018;53:1033-1040.

Address correspondence to: Abhishek Kumar, MVSc Germ-Plasm Centre Division of Animal Reproduction ICAR-Indian Veterinary Research Institute Izatnagar 243122 India

E-mail: abhiawadhesarita@gmail.com 